\title{
The Causes of Secondary Epilepsy in Epileptic Patients Referred to Neurology Clinics of Mashhad Hospitals
}

\author{
Parsa Ghazi Hosseini, ${ }^{1}$ Seyyed Mehran Homam, ${ }^{1}$ Parmis Ghazi Hosseini, ${ }^{2}$ Nadia \\ Badriahmadi, ${ }^{1}$ and Alireza Shamsi, \\ ${ }_{1}^{1}$ Medical Department, Islamic Azad University, Mashhad Branch, Mashhad, IR Iran \\ ${ }^{2}$ Faculty of Medicine, Mashhad University of Medical Sciences, Mashhad, IR Iran \\ ${ }^{3}$ Department of Psychiatry, Ali Ibnabitaleb Hospital, Zahedan University of Medical Sciences, Zahedan, IR Iran \\ ${ }^{*}$ Corresponding Author: Alireza Shamsi, Department of Psychiatry, Ali Ibnabitaleb Hospital, Zahedan University of Medical Sciences, Zahedan, IR Iran. Tel: +98-5138414499, Fax: \\ +98-5138414051, E-mail: telehealth.ir@gmail.com
}

Received 2015 January 27; Revised 2015 August 15; Accepted 2015 September 15.

\begin{abstract}
Background: Epilepsy is a group of disorders characterized by recurrent unprovoked seizures. It is recognized as one of the most common neurological diseases affecting different age groups.

Objectives: This study aimed to determine the causes of secondary epilepsy in patients with epilepsy at Mashhad hospitals in 2011 - 2012. Patients and Methods: In this cross-sectional, descriptive study, 300 participants were selected via available sampling from patients with epilepsy referred to hospitals affiliated to Islamic Azad University of Mashhad. Diagnosis of epilepsy was based on the criteria of the International League Against Epilepsy. Patients' demographic and medical profile questionnaires were completed, using clinical examinations, electroencephalography (EEG) and brain imaging.

Results: In this study, $54 \%$ and $46 \%$ of participants were male and female, respectively (mean age $=31.5 \pm 15.3$ years). Head trauma was the most common cause of secondary epilepsy, observed in $26 \%$ of patients. Brain tumor (9.7\%), stroke (9.3\%), brain infection ( $8.3 \%$ ), metabolic disease (3.3\%) and birth trauma or congenital anomalies (2.3\%) were other causes. Findings of the last performed EEG were normal and abnormal in $49 \%$ and $51 \%$ of participants, respectively. Moreover, results of brain imaging were normal in $85.3 \%$ and abnormal in $14.7 \%$ of subjects.

Conclusions: This study evaluated the causes of secondary epilepsy. Our findings showed that $45.3 \%$ of the subjects had secondaryepilepsy. Some patients presented with multiple conditions and there was more than one cause of secondary epilepsy in these cases. This study showed that the average age of patients with previous history of stroke was higher than that of other participants. However, previous history of stroke and head trauma mostly observed in males.
\end{abstract}

Keywords: Secondary epilepsy, Primary Epilepsy, Seizure

\section{Background}

Epilepsy is a group of disorders characterized by recurrent unprovoked seizures.

Seizure is a transient neurologic dysfunction caused by sudden abnormal firing of cerebral neurons $(1,2)$. Physical and behavioral changes occur after an episode of abnormal electrical activity in the brain. Seizures occur as a result of abnormal, extreme or synchronous neuronal activity in the brain $(3,4)$.

Loss of control and violent shaking are recognized symptoms of epilepsy. This condition can be accompanied by dramatic, noticeable symptoms or even no symptoms at all. Diagnosis and treatment of seizures are of high importance; some seizures can be a symptom of other medical conditions or even lead to further injuries. If specific problems are found on either electroencephalogram (EEG) or brain images, treatment is normally required even after the first seizure $(5,6)$.
Today, epilepsy is recognized as one of the most common neurological diseases, affecting different age groups. In total, incidence and prevalence of epilepsy in different countries range from 3 to 5 and 5 to 10 per 1000 people, respectively $(7,8)$. Lifetime risk of epilepsy has been estimated as 3\% and its incidence rate is higher in developing countries (9).

Regarding the etiology of epilepsy, seizures can be classified as either idiopathic (primary) or symptomatic (secondary). In idiopathic seizures, electrical discharge in the brain increases by aging and genetic defects (without any underlying structural abnormalities). Symptomatic seizures (secondary) can be caused by illness, metabolic defects and brain damages including focal brain lesions, abscesses, tumors, vascular malformations and other cerebrovascular accidents (10).

Although the etiology of epilepsy varies with age, un-

Copyright ( 2015, Shiraz University of Medical Sciences. This is an open-access article distributed under the terms of the Creative Commons Attribution-NonCommercial 4.0 International License (http://creativecommons.org/licenses/by-nc/4.0/) which permits copy and redistribute the material just in noncommercial usages, provided the original work is properly cited. 
provoked seizures are the most common cause of epilepsy for all age groups. Vascular malformations of the brain and head traumas are known as the most common causes of secondary epilepsy (11). In total, clinical examinations (to search for systemic symptoms of infection or disease), experimental studies (routine laboratory studies and blood tests to diagnose the most common metabolic causes of seizures) and electrophysiological studies using EEG and brain imaging (to detect underlying structural abnormalities) are necessary for definitive diagnosis and treatment of epilepsy.

Sudden unexplained death in patients with epilepsy is 25 times higher than the general population. Since mortality rate in patients with secondary epilepsy is higher than those with the idiopathic type, studies for determining the causes of secondary epilepsy are necessary (12). This study aimed to determine the causes of secondary epilepsy and evaluate the frequency of these factors in patients with epilepsy, referred to neurology clinics of Mashhad hospitals, located in Northeast of Iran in 2011 - 2012.

\section{Objectives}

This study aimed to determine the causes of secondary epilepsy in patients with epilepsy at Mashhad hospitals in 2011- 2012.

\section{Patients and Methods}

In this cross-sectional, descriptive study, participants were selected via available sampling among patients referred to neurology clinics of 22th Bahman and 17th Shahrivar hospitals (affiliated to Islamic Azad University of Mashhad). The sample included subjects with a definite diagnosis of epilepsy according to the criteria of the International League against Epilepsy and the sample size was calculated as 274 subjects. Finally, 300 participants were recruited.

\subsection{Inclusion and Exclusion Criteria}

In this study, inclusion criteria were as follows:1) definitive diagnosis of epilepsy; 2) availability of EEG and imaging findings; and 3) age above 15 years. Exclusion criteria were as follows: 1) single seizures; 2) patient's lack of cooperation; 3) absence of clinical records and 4) unavailability of EEG and imaging findings. Moreover, patients with seizures due to use of proconvulsant medications were excluded from the study.

\subsection{Ethical Considerations}

Participants were assured about the confidentiality of data. Informed consents were obtained from participants and questionnaires were completed by the researchers. Since all examinations and clinical measures were for the purpose of epilepsy diagnosis, patients did not pay any additional costs.

\subsection{Research Methods}

Diagnosis of epilepsy was based on the criteria of the
International League Against Epilepsy (13). Another criterion for diagnosis of epilepsy was an interval of more than 24 hours between two seizures due to pathological neuronal discharge in brain. Patients' demographic and medical profile questionnaires were completed based on clinical examinations, EEG and brain imaging findings. Then, the data were recorded based on the etiology of disease and clinical findings.

The data were recorded and analyzed by SPSS version 18 (IBM Corporation) and Microsoft Excel (Microsoft Corporation). Mc Nemar, Chi-square and t-test were used for data analysis.

\section{Results}

In this study, $54 \%(n=162)$ and $46 \%(n=138)$ of the participants were male and female, respectively. The mean age of subjects was $31.5 \pm 15.3$ years. Most patients were within the age range of 21 - 30 years (approximately34\%).

Regarding marriage status, $57 \%$ and $43 \%$ of subjects were married and single, respectively. Regarding participants' education level, $39.3 \%$ of the subjects had less than high school education and $60.7 \%$ high school diploma and above.

In this study, distribution of samples based on the causes of secondary epilepsy was assessed. Our findings showed that $45.3 \%$ of the subjects had secondary epilepsy. History of head traumas leading to decrease in level of consciousness was the most common cause of secondary epilepsy, found in $26 \%$ of patients. In addition, in $9.7 \%$, 9.3\%, $8.3 \%$ and $3.3 \%$ of patients causes of epilepsy included brain tumor, stroke, infection and history of metabolic diseases, respectively. In addition, $2.3 \%$ of patients had a birth trauma or congenital anomalies. Since some patients presented with multiple conditions, there was more than one cause of secondary epilepsy in these cases.

Causes of secondary epilepsy, based on the type of disease, are shown in Table 1. Distribution of age according to the causes of secondary epilepsy is shown in Table 2 . According to the results in Table 2, there was a significant association between the mean age of participants and history of stroke and brain tumor. In total, the mean age of subjects with secondary epilepsy was significantly higher than those with primary epilepsy $(\mathrm{P}=0.045)$.

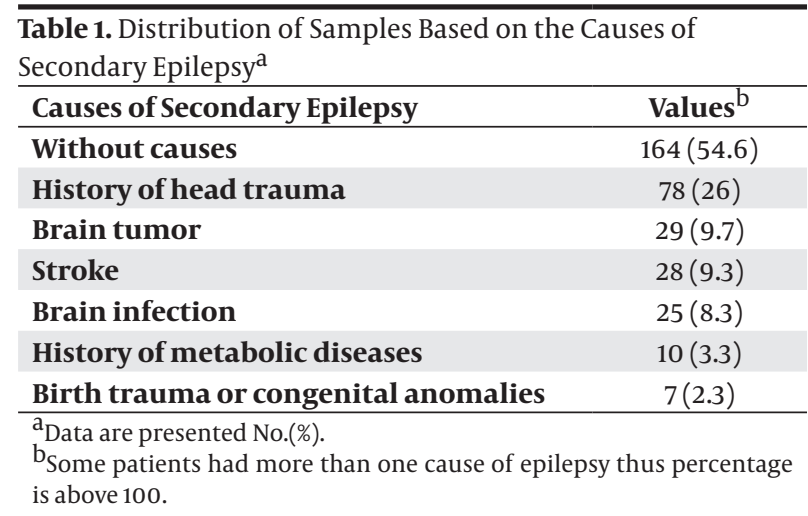


Distribution of gender based on the presence or absence of secondary epilepsy is shown in Table 3. In addition, distribution of gender based on the onset of symptoms and diagnosis is shown in Table 4. Overall, 93.5 \pm 107.1 and 82.7 \pm 92.9 months had passed since the onset of symptoms and diagnosis; epilepsy was diagnosedapproximately10 months after the onset of symptoms.

Regarding medication use, $28.3 \%$ of the patients did not take any medications. Sodium valproate (about 40.7\%) and carbamazepine (about 35.3\%) were the most commonly used medications followed by phenobarbital (17.7\%), often used with sodium valproate and carbamazepine. Some patients used more than one medication and 85 subjects did not take any medications. Overall, 146, 36 and 21 people used one-drug, two-drug and three-drug regimens, respectively.

Frequency distribution showed that the mean number of seizures was $11.3 \pm 15.3$. Subjects with less than five seizures had the highest frequency (about 44.3\%). The number of seizureswere $6-10,11-20$ and $21-30$ in $20.6 \%$,
$16.7 \%$ and $11.3 \%$ of cases, respectively; also, it was repeated over30 times in $7 \%$ of the subjects.

Regarding clinical examination, $7.7 \%$ of cases had focal neurologic signs and $91.3 \%$ had no focal neurologic signs. The last EEG findings were reported normal and abnormal in $49 \%$ and $51 \%$ of patients, respectively. Moreover, in $85.3 \%$ and $14.7 \%$ of subjects, results of brain imaging were normal and abnormal, respectively.

A comparison between clinical examination, EEG and brain imaging findings is shown in Table 5. According to this table, abnormal clinical examination results were confirmed by the last EEG findings; therefore, there was a significant correlation between clinical examination and last EEG results $(\mathrm{P}<0.0001)$. Moreover, there was a significant association between abnormal results of clinical examination and abnormal brain imaging findings $(\mathrm{P}=0.003)$; in fact, abnormal results of clinical examination were confirmed by brain imaging. In addition, there was a significant association between abnormal EEG and brain imaging results $(\mathrm{P}<0.0001)$.

\begin{tabular}{lcccc}
\hline Table 2. Distribution of Age Based on the Presence or Absence of Causes of Secondary Epilepsy & & & \\
\hline Variables & Absencea & Presencea & T-Test & PValue \\
\hline Causes & $29.69 \pm 14.69$ & $33.28 \pm 15.80$ & 2.012 & 0.045 \\
History of stroke & $30.00 \pm 13.93$ & $48.09 \pm 14.82$ & 6.503 & $>0.0001$ \\
Brain tumor & $29.97 \pm 14.18$ & $47.70 \pm 14.79$ & 6.371 & $>0.0001$ \\
History of head trauma & $30.90 \pm 13.50$ & $33.93 \pm 19.34$ & 1.508 & 0.131 \\
History of brain infection & $31.89 \pm 15.92$ & $29.92 \pm 9.72$ & 0.68 & 0.50 \\
History of metabolic diseases & $31.89 \pm 15.58$ & $25.82 \pm 11.52$ & 1.22 & 0.22 \\
\hline Birth trauma or congenital anomalies & $31.69 \pm 15.44$ & $31.57 \pm 14.43$ & 0.20 & 0.98 \\
\hline
\end{tabular}

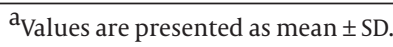

Table 3. Distribution of Gender Based on the Presence or Absence of Causes of Secondary Epilepsy ${ }^{\mathrm{a}}$

\begin{tabular}{|c|c|c|c|c|c|}
\hline & \multirow[t]{2}{*}{ Total } & \multicolumn{2}{|c|}{ Gender } & \multirow[t]{2}{*}{$\chi^{2}$} & \multirow[t]{2}{*}{ P Value } \\
\hline & & Male & Female & & \\
\hline Without causes & 54.7 & 43 & 46 & 0.307 & 0.38 \\
\hline With causes & 45.3 & 57 & 54 & & \\
\hline Without history of stroke & 91 & 86 & 96 & 10.71 & 0.002 \\
\hline With history of stroke & 9 & 14 & 4 & & \\
\hline Without history of head trauma & 74 & 64 & 86 & 18.15 & $<0.0001$ \\
\hline With history of head trauma & 26 & 36 & 14 & & \\
\hline Without brain tumor & 90 & 88 & 93 & 1.813 & 0.178 \\
\hline With brain tumor & 10 & 12 & 7 & & \\
\hline Without history of brain infection & 92 & 94 & 89 & 2.04 & 0.152 \\
\hline With history of brain infection & 8 & 6 & 11 & & \\
\hline Without birth trauma & 98 & 100 & 95 & Fisher's Exact Test & 0.004 \\
\hline With birth trauma & 2 & 0 & 5 & & \\
\hline Without history of metabolic diseases & 97 & 96 & 98 & Fisher's exact test & 0.349 \\
\hline With history of metabolic diseases & 3 & $4 \%$ & 3 & & \\
\hline
\end{tabular}

a Data are presented as \%. 
Ghazi Hosseini P et al.

\begin{tabular}{lcc}
\hline Table 4. Distribution of Epilepsy According to the Onset of Symptoms and Time of Diagnosis & \\
\hline Onset of Symptoms and Time of Diagnosis & Onset of Symptoms & Time of Diagnosis \\
\hline Less than a year & $61(20.3)$ & $76(25.3)$ \\
\hline $\mathbf{1 - 5}, \mathbf{y}$ & $122(40.7)$ & $123(41.0)$ \\
$\mathbf{6}-\mathbf{1 0}, \mathbf{y}$ & $44(14.7)$ & $32(10.7)$ \\
$\mathbf{1 1 - 1 5}, \mathbf{y}$ & $29(9.7)$ & $29(9.7)$ \\
$\mathbf{1 6 - 2 0}, \mathbf{y}$ & $22(7.3)$ & $21(7.0)$ \\
\hline $\mathbf{2 1}-\mathbf{2 6}, \mathbf{y}$ & $7(2.3)$ & $11(3.7)$ \\
\hline Above 26, y & $15(5.0)$ & $8(2.7)$ \\
\hline Total & $300(100)$ & $300(100)$ \\
\hline
\end{tabular}

$\mathrm{a}_{\text {Values are presented as No.(\%). }}$

\begin{tabular}{|c|c|c|c|c|}
\hline & \multicolumn{3}{|c|}{ Clinical Examination } & \multirow[t]{2}{*}{ P Value } \\
\hline & Normal & Abnormal & Total & \\
\hline Brain imaging & & & & 0.003 \\
\hline Normal & 82.7 & 2.7 & 85.3 & \\
\hline Abnormal & 8.7 & 6.0 & 14.7 & \\
\hline Total & 91.3 & 8.7 & 100 & \\
\hline EEG results & & & & $<0.0001$ \\
\hline Normal & 49.0 & 0 & 49.0 & \\
\hline Abnormal & 42.3 & 8.7 & 51.0 & \\
\hline Total & 91.3 & 8.7 & 100 & \\
\hline
\end{tabular}

The results showed no significant difference between the onset of treatment and beginning of seizures. However, in men, the onset of treatment was more synced with the onset of seizures, compared to women. Moreover, there was a significant difference between education level and start of treatment.

\section{Discussion}

Since the epidemiology of epilepsy is dependent on factors such as age, education level, geographical location, socio-economic status and demographic characteristics, evaluation of epilepsy frequency in each region is necessary to diagnose, control and treat this condition. According to the study by Bhalla et al., evaluation of the etiology of epilepsy is necessary to obtain more information about this disease (14).

In total, this study showed that the average age of patients with stroke and brain tumor was higher than other patients. Furthermore, subjects with secondary epilepsy were older than those with idiopathic epilepsy. Stroke and brain tumor were more common in males than females.

According to the results of this study, most patients referred during the last five years, started their treatment earlier than those referred before the last five years. In addition, patients with higher education level started their treatments earlier than others. This may be due to increased public awareness by media, increased education level and access to diagnostic and healthcare services.

In this study, most patients were 21 - 30 years old. In other similar studies, patients' average age was not specified or the subjects were within a limited age range. For instance, Tabatabaei et al. performed a study on patients above 60 years over ten years (15).

In our study, most patients with epilepsy had high school diploma or above. Moreover, the marriage status was assessed.

As previous studies, epilepsy is often idiopathic with unknown causes (16); these findings are consistent with the results of our study. For instance, according to the study by Xiao et al., unknown or idiopathic epilepsy was more common than secondary epilepsy (17).

Our study showed that head trauma was the most common cause of secondary epilepsy, which is in congruence with other similar studies $(16,17)$. In another paper, the most common causes of epilepsy were head trauma, cerebrovascular diseases and central nervous system infections, respectively (18).

A follow-up study of patients with epilepsy due to head trauma and stroke showed that head trauma increased the incidence of seizures, which was almost 12 times higher than the normal population (19). Furthermore, in Tabatabaei's study, the rate of idiopathic epilepsy was 38\% 
in patients above 60 years. The most common differential diagnoses were syncope and cardiovascular disorders. In addition, $27 \%$ and $24 \%$ had systemic metabolic disorders and cerebrovascular diseases, respectively (15).

In the present study, clinical examination and brain imaging findings had normal findings in most subjects; EEG findings were normal in a half of participants. In fact, a combination of clinical examination and EEG is a reliable method for identifying secondary epilepsy; this was consistent with the findings of Shorvon and colleagues. However, according to the mentioned study, identification of the causes of secondary epilepsy is troublesome, since they are dependent on socio-economic factors and application of diagnostic methods (20).

In total, the results of our research were consistent with other similar studies including Alajbegovic et al.(21) and Shichuo et al. (19) investigations. One of the most important findings of this study was that the last EEG results confirmed the abnormal findings of clinical examination. In other words, if EEG results are abnormal, clinical examination findings are abnormal, as well. In addition, abnormal results of clinical examination were confirmed by brain imaging findings. Moreover, there was a significant association between abnormal results of EEG and brain imaging findings $(\mathrm{P}<0.0001)$.

Therefore, evaluation of epilepsy frequency in each region is necessary to diagnose, control and treat this condition. We should assess epilepsy epidemiology and factors that affect it such as age, geographical location and other demographic characteristics. This study showed that age and gender were influential factors and head trauma was the most common cause of secondary epilepsy. The last EEG results confirmed abnormal findings of clinical examination and abnormal results of clinical examination were confirmed by brain imaging findings.

\section{Acknowledgments}

We would like to thank all people who participated in this study.

\section{Footnote}

Authors' Contribution:Study concept and design: Seyyed Mehran Homam. Acquisition of data: Parmis Ghazi Hosseini. Analysis and interpretation of data: Nadia Badriahmadi, Alireza Shamsi. Drafting of the manuscript: Parsa Ghazi Hosseini.

\section{References}

1. Chang BS,Lowenstein DH.Epilepsy.NEnglJMed.2003;349(13):1257-
66. doi: 10.1056/NEJMra022308. [PubMed:14507951]

2. Fisher RS, Acevedo C, Arzimanoglou A, Bogacz A, Cross JH, Elger CE, et al. ILAE official report: a practical clinical definition of epilepsy. Epilepsia. 2014;55(4):475-82. doi: 10.1111/epi.12550. [PubMed: 24730690]

3. Schmitz B,, Tettenborn B,, Schomer DL. The Paroxysmal Disorders. Cambridge: Cambridge University Press; 2010.

4. Meneret A, Gaudebout C, Riant F, Vidailhet M, Depienne C, Roze E. PRRT2 mutations and paroxysmal disorders. Eur J Neurol. 2013;20(6):872-8. doi: 10.1111/ene.12104. [PubMed: 23398397]

5. Yang P, You G, Zhang W, Wang Y, Wang Y, Yao K, et al. Correlation of preoperative seizures with clinicopathological factors and prognosis in anaplastic gliomas: a report of 198 patients from China. Seizure. 2014;23(10):844-51. doi: 10.1016/j.seizure.2014.07.003. [PubMed: 25153654]

6. Engel J. Seizures and epilepsy. New York: Oxford University Press; 2013.

7. Silbergleit R, Lowenstein D, Durkalski V, Conwit R, on behalf of the NETT Investigators. Lessons from the RAMPART study--and which is the best route of administration of benzodiazepines in status epilepticus. Epilepsia. 2013;54 Suppl 6:74-7. doi: 10.1111/ epi.12284. [PubMed: 24001080]

8. Herzog AG. Catamenial epilepsy: definition, prevalence pathophysiology and treatment. Seizure. 2008;17(2):151-9. doi:10.1016/j. seizure.2007.11.014. [PubMed:18164632]

9. Yemadje LP, Houinato D, Quet F, Druet-Cabanac M, Preux PM. Understanding the differences in prevalence of epilepsy in tropical regions. Epilepsia. 2011;52(8):1376-81. doi: 10.1111/j.15281167.2011.03099.x. [PubMed: 21627649]

10. Ropper A,, Samuels M,, Klein J. Adams and Victor's Principles of Neurology. 10th ed. Washington DC: McGraw Hill Professional; 2014.

11. Tetzlaff R, Elger CE, Lehnertz K. Recent Advances in Predicting and Preventing Epileptic Seizures. Singapore: World Scientific; 2013.

12. Mueller W,M, Anderson CT. Epilepsy Simplified. New York: Lippincott Williams \& Wilkins; 2013.

13. Commission on Epidemiology and Prognosis ILAE. Epilepsia: 1993. Guidelines for epidemiologic studies on epilepsy.

14. Bhalla D, Godet B, Druet-Cabanac M, Preux PM. Etiologies of epilepsy: a comprehensive review. Expert Rev Neurother. 2011;11(6):861-76. doi:10.1586/ern.11.51. [PubMed:21651333]

15. Tabatabaei SS, Delbari A, Salman-Roghani R, Shahgholi L, Fadayevatan R, Mokhber N, et al. Seizures and epilepsy in elderly patients of an urban area of Iran: clinical manifestation, differential diagnosis, etiology, and epilepsy subtypes. Neurol Sci. 2013;34(8):1441-6. doi: 10.1007/s10072-012-1261-0. [PubMed: 23232961]

16. Greenberg D,, Aminoff M,, Simon R. Clinical Neurology 8/E. Washington DC: McGraw-Hill Education; 2012.

17. Xiao B, Huang ZL, Zhang H, Liu YS, Yuan XR, Zhang N, et al. Aetiology of epilepsy in surgically treated patients in China. Seizure. 2004;13(5):322-7. doi: 10.1016/j.seizure.2003.08.005. [PubMed: 15158703]

18. Mac TL, Tran DS, Quet F, Odermatt P, Preux PM, Tan CT. Epidemiology, aetiology, and clinical management of epilepsy in Asia: a systematic review. Lancet Neurol. 2007;6(6):533-43. doi: 10.1016| S1474-4422(07)70127-8. [PubMed:17509488]

19. Shichuo L, Jiaqiang W, Jianzhong W. Cerebrovascular and posttraumatic epilepsy. Becker Open Access Publications; 2013.

20. Shorvon SD. The causes of epilepsy: changing concepts of etiology of epilepsy over the past 150 years. Epilepsia. 2011;52(6):103344. doi: 10.1111/j.1528-1167.2011.03051.x. [PubMed: 21480878]

21. Alajbegovic A, Loga N, Alajbegovic S, Suljic E. Characteristics of symptomatic epilepsy in patients with brain tumours. Bosn J Basic Med Sci. 2009;9(1):81-4. [PubMed:19284401] 